\title{
Managing Landslide Dam Failure Risks
}

\author{
Limin Zhang ${ }^{1,2}$ \\ ${ }^{1}$ Hong Kong University of Science and Technology, Kowloon, Hong Kong, China \\ ${ }^{2}$ HKUST Shenzhen Research Institute, Shenzhen, China
}

doi: https://doi.org/10.21467/abstracts.93.53

\section{ABSTRACT}

The failure of a large dam can be disastrous. For example, the failure of the Banqiao dam in Henan, China, in August 1975 resulted in the loss of over 26,000 lives; the failure of the South Fork dam in Pennsylvania, USA, in 1,889 killed 2,209 people. Natural dams formed by landslides are particularly short lived and prone to failure. Particularly, a strong earthquake can lead to many landslide dams. For example, the Wenchuan earthquake in 2008 triggered more than 60,000 landslides, over 250 of them blocked rivers and formed risky landslide dams.

Zhang et al. collected 1267 cases of landslide dam failure (Zhang et al. 2016). Statistics show that $91.8 \%$ of these dams failed by overtopping, $7.0 \%$ by piping and $1.2 \%$ by slope failure. Most of the dams failed by overtopping because no water-passing devices are available in natural dams. The lifespan of these landslide dams is typically short: $87 \%$ of them failed within one year, $71 \%$ within one month and $51 \%$ within one day. Due to the potentially short lifespan of landslide dams, once a landslide dam forms, a rapid dam risk assessment must be conducted and a risk management plan must be timely implemented.

The dam-break risk management plan aims at minimizing the possible consequences using either structural measures or non-structural measures. Structural measures are meant to drain the lake, lower the water level or slower down the erosion process so that the dam-breaching flood is reduced. Non-structural measures such as warning, sheltering and evacuationare meant to reduce the elements at risk so that the loss of human lives and properties can be minimised.

This paper outlines the principle of emergency dam-risk managementin both time and space.Two recent cases are presented to illustrate the principle. The evaluation of dam risks covers a large area along the river from the catchment upstream of the dam to the potential flood areas downstream of the dam(Figure 1). Several steps are often followed when evaluating the risks: hydraulic parameter forecasting, dam-break probability evaluation, dam breaching simulation, flood routing simulation and flood consequence evaluation. Risk mitigation measures and their effectiveness shall be evaluated in an iterative manner.

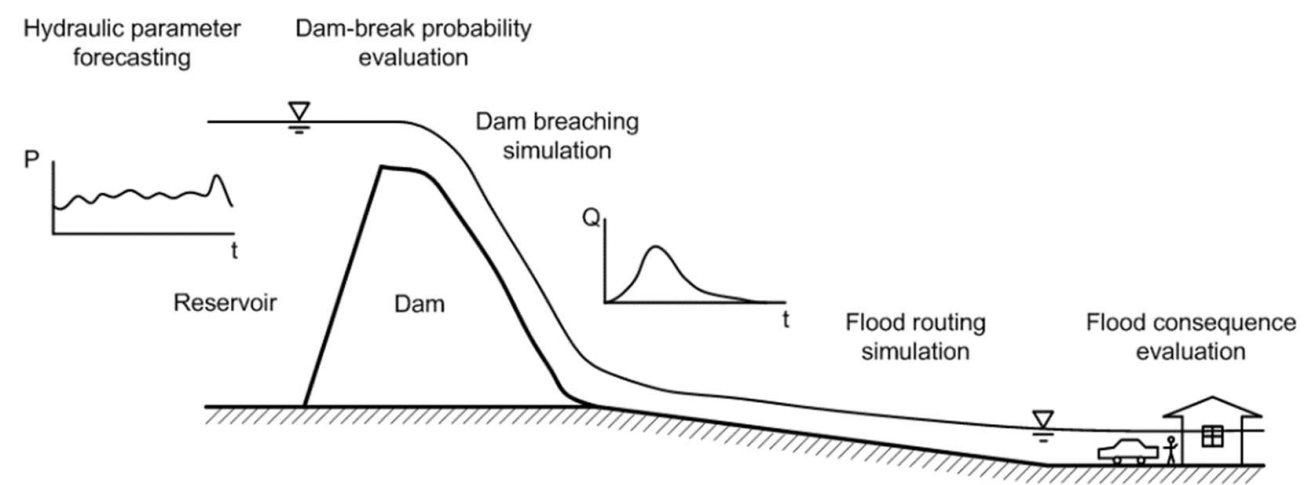

Fig. 1. Some main tasks of dam-breaching risk analysis

(C) 2020 Copyright held by the author(s). Published by AIJR Publisher in "Abstracts of The Second Eurasian RISK-2020 Conference and Symposium" April 12- 19, 2020, Tbilisi, Georgia. Jointly organized by AMIR Technical Services LLC, Georgian Technical University, Institute of Geography (Kazakhstan) and Russian Institute of Petroleum Geology and Geophysics. 
The Second Eurasian RISK-2020 Conference and Symposium

Jinsha River landslide dam failure in 2018. The Jinsha River, the upper reach of the Yangtze River, was dammed twice recently at Baige, Tibet, one on 10 October 2018 and the other on 3 November 2018. Accordingly, two large landslide dams, $61 \mathrm{~m}$ and $96 \mathrm{~m}$ in height to the lowest dam crest, were formed in a three-week interval. In managing the landslide dam risk, rapid prediction of the dam breaching hydrograph and breach geometric parameters of the two landslide dams was performed before the breaching of the two landslide dams using both erosion-based empirical equations and numerical simulation. A diversion channel $15 \mathrm{~m}$ in depth was excavated on the second dam, which successfully lowered the breaching peak flow rate to $33,900 \mathrm{~m}^{3} / \mathrm{s}$ (Figure 2). Corresponding flood routing analysis was also performed to evaluate the potential flood zones and facilitate evacuation of people up to $700 \mathrm{~km}$ downstream the dam. Existing reservoirs downstream the dam were utilised to regulate the dam-breaching flood.

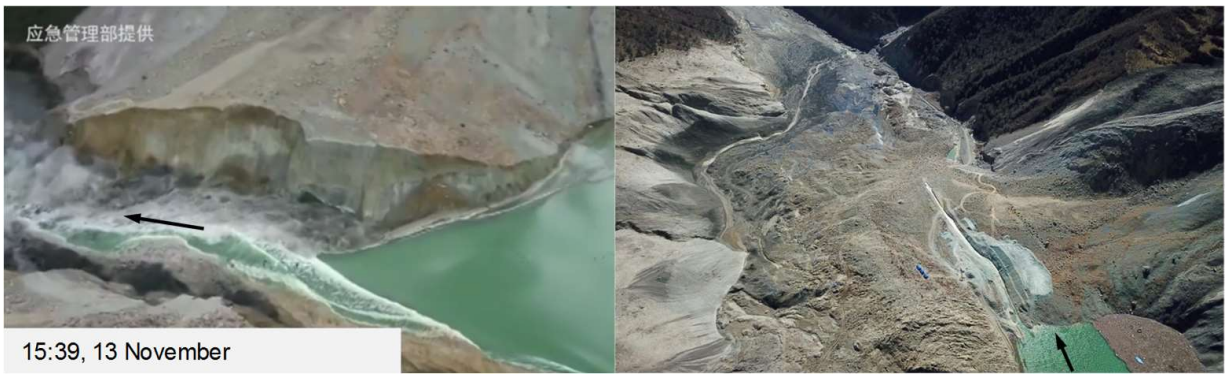

Figure 2. The Jinsha River landslide dam breaching in November 2018.

Tangjiashan landslide dam failure in 2008. The Tangjiashan landslide dam was formed during the 2008 Wenchuan earthquake, with a height of 82-124 m, a length along the river of $803 \mathrm{~m}$, a length across the river of $611 \mathrm{~m}$, and a lake volume of 316 million $\mathrm{m}^{3}$. Rapid and numerical analyses were performed to estimate the dam-breaching flood hydrograph and flood routing. A staged risk assessment was conducted to evaluate the risks at different stages based on hydrologic and geological information available at each stage (Peng and Zhang 2013). A $12 \mathrm{~m}$ deep division channel was excavated to reduce the risk. More than 0.2 million people were evacuated 10 days before the dam breached.

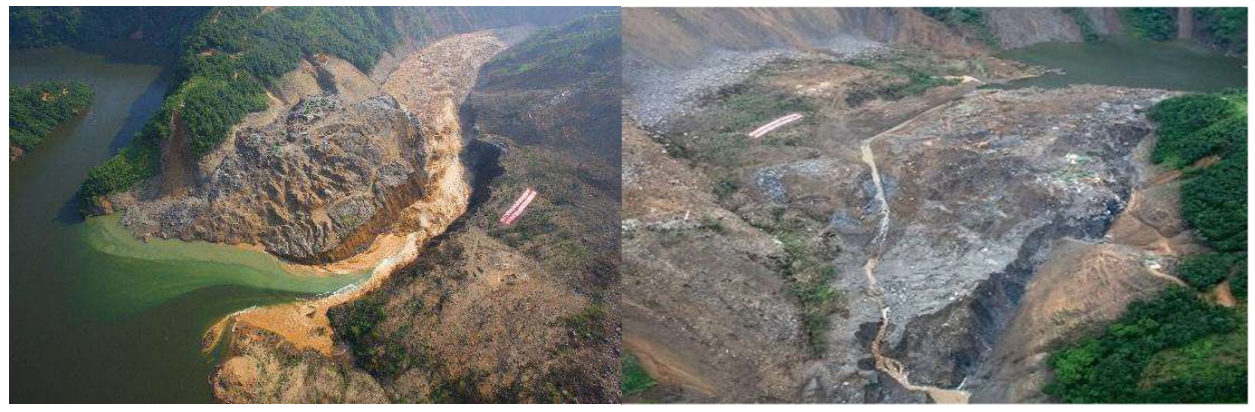

Figure 3. The Tangjiashan landslide dam breaching in June 2008.

Acknowledgements. This research is supported by the National Key Technologies Research and Development Program of the Ministry of Science and Technology of China (Project No. 2018YFC1508600).

\section{References}

Peng, M. and Zhang,L.M. (2013). Dynamic decision making for dam-break emergency management - Part 2: Application to Tangjiashan Landslide Dam failure. Natural Hazards and Earth System Sciences 13: 439-454.

Zhang,L.M., Peng, M., Chang, D.S. and Xu, Y. (2016). Dam Failure Mechanisms and Risk Assessment, John Wiley \& Sons, London, 493 pp.

Zhang,L.M., Xiao, T., He, J. and Chen, C. (2019). Erosion-based analysis of breaching of Baige landslide dams on the Jinsha River, China, in 2018. Landslides 16:1965-1979. 